\title{
Clinical study of neck space abscesses in rural population.
}

\author{
${ }^{1}$ Dr.S.V.Bhise, ${ }^{2}$ Dr.Faizan Rahmani, ${ }^{3}$ Dr. A.M. Pawde \\ ${ }^{1}$ Assistant prof. Dept ENT S.R.T.R.G.M.C.Ambajogai Maharashtra \\ ${ }^{2}$ Asst. Prof. Dept. of ENT GMC Kolhapur \\ ${ }^{3}$ Prof and head Dept. of ENT S.R.T.R.G.M.C.Ambajogai Maharashtra
}

\begin{abstract}
Neck space infections affect fascial compartments of head, neck and their contents. In this study we aimed at study of different aspects of neck space abscesses in scenario of rural population.In present study 54 patients were studied who were presented to ENT OPD and diagnosed as having neck space abscesses. Most commonly involved space was peritonsillar space. Male predominance was noted. Most common organism found on pus culture was coagulase positive staphylococcus $(29.62 \%)$, sensitivity was highest for aminoglycosides and cephalosporins $78.57 \%$ and $71.42 \%$ respectively.Resistance was highest for erythromycin and ciprofloxacin.
\end{abstract}

Key words; neck space abscesses, peritonsillar abscess, incision and drainage, antibiotic sensitivity

\section{Introduction:}

Neck space infections affect fascial compartment of head, neck and their contents. This concept has been recognized since antiquity as even Hippocrates has drawn attention to it. ${ }^{[1]}$ In recent years, several reports have described changing trends in neck space infections over time. Differences in incidence, age at presentation, anatomic location, and infecting organism have most commonly been noted. The most crucial issue is perhaps increasing microbial resistance. ${ }^{[2]}$

The increased prevalence of patients with immunodeficiency and inadequate antibiotic treatment has resulted in unusual clinical presentation and pathogens making the clinical diagnosis and treatment further difficult.

In this study we aimed to study these different aspects of neck space abscess in scenario of rural India.

\section{Materials \& Methods:} abscess.

The present study comprises 54 patients presenting in ENT OPD and diagnosed as having neck space Type of study: Prospective study

1) Inclusion criteria:

$>$ All age groups

$>$ With or without complication

$>$ Patients of following space abscesses

Retropharyngeal

Parapharyngeal

2) Exclusion criteria:

$>$ Patients with co morbid diseases like TB,DM,HIV

3) Ethical clearance:

Prior to commencement, the study was approved by the ethical committee of the medical college.

4) Informed consent:

All the patients fulfilling the selection criteria were explained about the purpose of study and a written consent was obtained from them to participate in the study before enrollment.

5) Method of collection of data:

Before enrollment, demographic data such as age, sex, detailed history and examination were recorded on a predesigned and pretested proforma. At the time of first visit presence of pus was confirmed by needle aspiration and sent for microbiological studies and sensitivity.

6) CT scan was carried out only in cases of suspected complications and in cases where deep spaces like retropharyngeal and parapharyngeal were involved. 
7) Because of unavailability of anaerobic culture facilities, pus was checked for presence of aerobic bacteria only and involvement of anaerobic organism was judged by presence of foul smelling pus.

Sensitivity was checked for following drugs.

Penicillin (Amoxycillin OR Ampicillin )

Cephalosporins ( Ceftraixone OR Cefotaxime )

Aminoglycosides ( Amikacin OR Gentamycin )

Cotrimoxazole

Ciprofloxacin

Erythromycin

8) Proper medical and surgical interventions were taken and recorded. All patients were admitted except few who were not willing for admission. Empirical treatment was initiated with combination of

1) inj. Cefotaxim $1 \mathrm{gm}$ i.v. 8 hourly

2) inj. Gentamycin $80 \mathrm{mg}$ i.v. 12 hourly

3) inj. Metronidazole 100 cc i.v. 8 hourly

Needle aspiration was maximally tried twice. If presence of pus was still suspected then patient was posted for incision and drainage.

In cases of burst abscess, only dilatation with dressing was done under antibiotic cover.

Incision and drainage was carried out under surface anaesthesia with ethyl chloride spray and minimal sedation. In cases where there was possibility of aspiration endotracheal intubation or tracheostomy was carried out.

10) In cases of recurrent peritonsillar abscess, tonsillectomy was performed after 6 weeks.

11) Patients were followed at 1 week and 1 month.

12) Data were analyzed by using proper statistical methods and $p$ value $<0.05$ was considered significant.

\section{Results:}

Graph 1: Distribution Of Cases According To Spaces Involved:

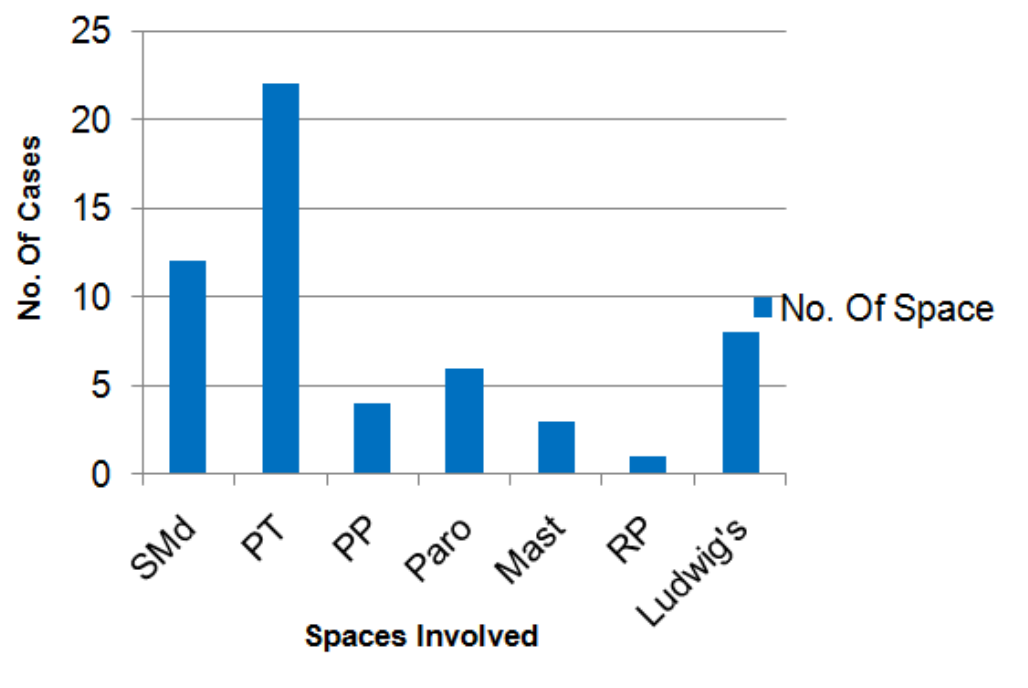




\section{GRAPH 2 : AGE DISTRIBUTION OF CASES:}

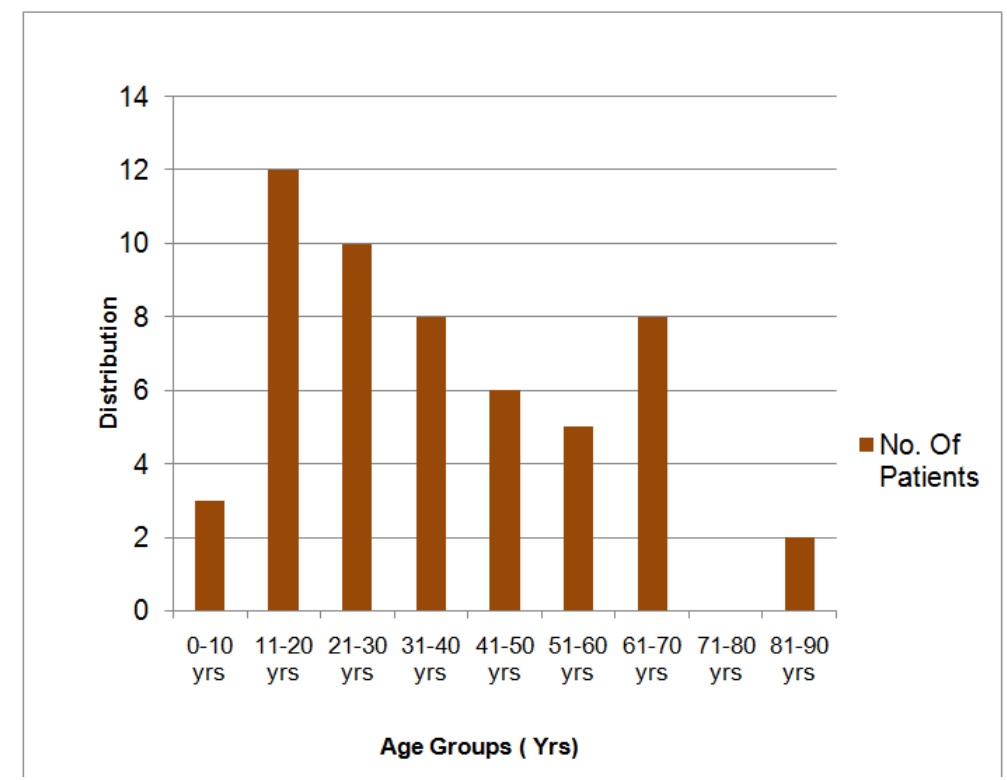

Table 4: Distribution According To Presenting Symptoms:

\begin{tabular}{|l|l|l|}
\hline SYMPTOM & NO. OF PATIENTS & $\begin{array}{l}\text { PERCENT } \\
(\mathrm{n}=54)\end{array}$ \\
\hline Pain While Opening Mouth & 51 & 94.44 \\
\hline Fever & 50 & 92.59 \\
\hline Trismus & 46 & 85.18 \\
\hline Pain In Neck & 36 & 66.66 \\
\hline Odynophagia & 34 & 62.96 \\
\hline Dysphagia & 34 & 62.96 \\
\hline Swelling In Neck & 33 & 61.11 \\
\hline Pain In Throat & 30 & 55.55 \\
\hline Salivation disturbances & 27 & 50.00 \\
\hline Toothache & 19 & 35.18 \\
\hline Earache & 18 & 33.33 \\
\hline Change In Voice & 14 & 25.92 \\
\hline
\end{tabular}

Graph 4 : Distribution Of Cases According To Etiological Factors:

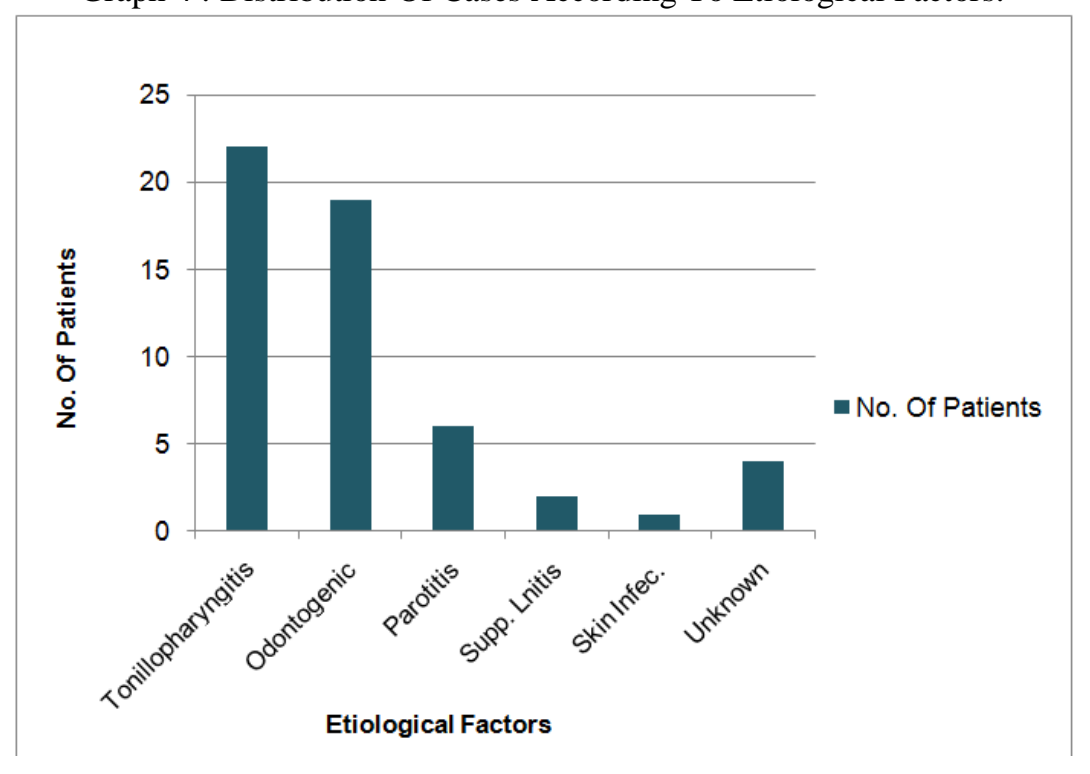


Table 8: Various Organisms Found On Pus Culture:

\begin{tabular}{|l|l|l|}
\hline Organisms & No. Of Patients & $\begin{array}{l}\text { Percent Of Total } \\
(\mathrm{n}=54)\end{array}$ \\
\hline Staphylococcus & & \\
\hline C+ & & 29.62 \\
\hline C- & 16 & 16.66 \\
\hline Streptococcus & 09 & 11.11 \\
\hline Klebsiella & 06 & 7.40 \\
\hline Pseudomonas & 04 & 5.55 \\
\hline E. Coli & 03 & 5.55 \\
\hline Enterococcus & 03 & 3.70 \\
\hline No Organism Grown & 02 & 22.22 \\
\hline
\end{tabular}

Table 10: Sensitivity Of Microorganisms To Antibiotic:

\begin{tabular}{|l|l|l|l|l|l|}
\hline Antibiotics & $\begin{array}{l}\text { Sensitive In } \\
\text { Patients }\end{array}$ & $\begin{array}{l}\text { Percent Of } \\
\text { Total }(\mathrm{n}=42)\end{array}$ & $\begin{array}{l}\text { Resistant In } \\
\text { Patients }\end{array}$ & $\begin{array}{l}\text { Percent Of } \\
\text { Total }(\mathrm{n}=42)\end{array}$ & $\begin{array}{l}\text { P* } \\
\text { Value }\end{array}$ \\
\hline Aminoglyco. & 33 & 78.57 & 09 & 21.42 & 0.0001 \\
\hline Cephalospo. & 30 & 71.42 & 12 & 28.57 & 0.0001 \\
\hline Penicillin & 20 & 47.61 & 22 & 52.83 & 0.51 \\
\hline Cotrimoxazole & 19 & 45.23 & 23 & 54.76 & 0.24 \\
\hline Erythromy. & 16 & 38.09 & 26 & 61.90 & 0.002 \\
\hline Ciprofloxacin & 16 & 38.09 & 26 & 61.90 & $\mathbf{0 . 0 0 2}$ \\
\hline
\end{tabular}

$\mathrm{P}$ value by One Proportion Z Test

Table 11: Shows Sensitivity Of Individual Microorganisms To Antibiotic:

\begin{tabular}{|c|c|c|c|c|c|c|}
\hline Drugs & Penici. & Cephalo. & Cotrimox. & Erythrom. & Ciproflo. & Aminogly. \\
\hline \multicolumn{7}{|c|}{$\begin{array}{lll} & \text { Sensitivity in percentage } \\
\end{array}$} \\
\hline & \multicolumn{6}{|c|}{ Resistance in percentage } \\
\hline \multirow{2}{*}{$\begin{array}{l}\mathrm{C}+\text { Staph } \\
(\mathrm{n}=16)\end{array}$} & $37.5 \%$ & $68.75 \%$ & $50.00 \%$ & $43.75 \%$ & $43.75 \%$ & $93.75 \%$ \\
\hline & $62.5 \%$ & $31.25 \%$ & $50.00 \%$ & $56.25 \%$ & $56.25 \%$ & $6.25 \%$ \\
\hline \multirow{2}{*}{$\begin{array}{l}\text { C- staph. } \\
(\mathrm{n}=9)\end{array}$} & $100 \%$ & $0.00 \%$ & $77.77 \%$ & $77.77 \%$ & $44.44 \%$ & $100 \%$ \\
\hline & $0.00 \%$ & $100 \%$ & $22.22 \%$ & $22.22 \%$ & $55.55 \%$ & $0.00 \%$ \\
\hline \multirow{2}{*}{$\begin{array}{l}\text { Strepto. } \\
(n=6)\end{array}$} & $33.33 \%$ & $83.33 \%$ & $16.66 \%$ & $16.66 \%$ & $16.66 \%$ & $50.00 \%$ \\
\hline & $66.66 \%$ & $16.66 \%$ & $83.33 \%$ & $83.33 \%$ & $83.33 \%$ & $50.00 \%$ \\
\hline \multirow{2}{*}{$\begin{array}{l}\text { Klebsiella } \\
(\mathrm{n}=4)\end{array}$} & $50.00 \%$ & $50.00 \%$ & $0.00 \%$ & $25.00 \%$ & $25.00 \%$ & $50.00 \%$ \\
\hline & $50.00 \%$ & $50.00 \%$ & $100 \%$ & $75.00 \%$ & $75.00 \%$ & $50.00 \%$ \\
\hline \multirow{2}{*}{$\begin{array}{l}\text { Pseudom. } \\
(n=3)\end{array}$} & $33.33 \%$ & $100 \%$ & $33.33 \%$ & $0.00 \%$ & $33.33 \%$ & $33.33 \%$ \\
\hline & $66.66 \%$ & $0.00 \%$ & $66.66 \%$ & $100 \%$ & $66.66 \%$ & $66.66 \%$ \\
\hline \multirow{2}{*}{$\begin{array}{l}\text { E. Coli } \\
(n=3)\end{array}$} & $100 \%$ & $100 \%$ & $66.66 \%$ & $0.00 \%$ & $33.33 \%$ & $100 \%$ \\
\hline & $0.00 \%$ & $0.00 \%$ & $33.33 \%$ & $100 \%$ & $66.66 \%$ & $0.00 \%$ \\
\hline \multirow{2}{*}{$\begin{array}{l}\text { Entero. } \\
(n=2)\end{array}$} & $50.00 \%$ & $0.00 \%$ & $0.00 \%$ & $0.00 \%$ & $50.00 \%$ & $50.00 \%$ \\
\hline & $50.00 \%$ & $100 \%$ & $100 \%$ & $100 \%$ & $50.00 \%$ & $50.00 \%$ \\
\hline
\end{tabular}


Graph 8 : Distribution Of Cases According To Treatment Modality Employed:

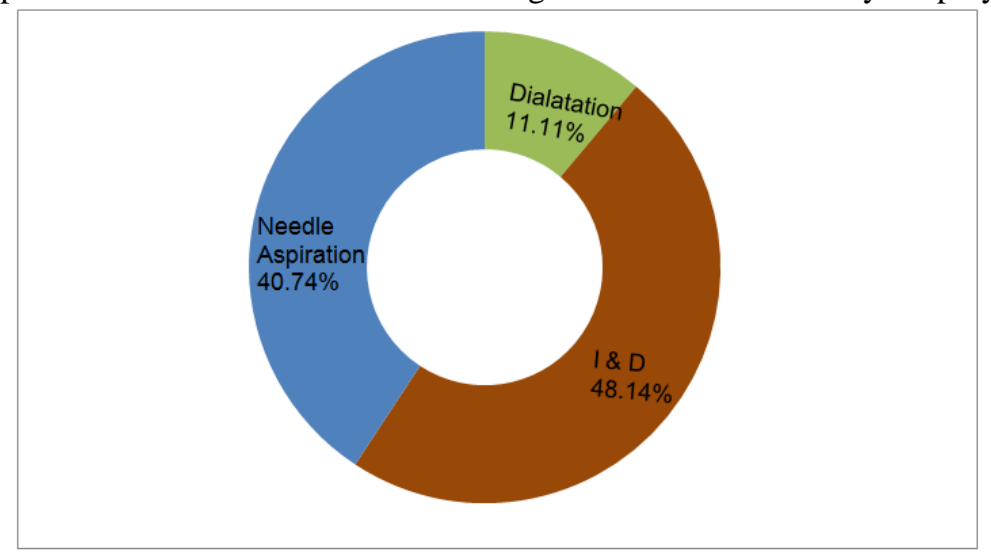

\section{Discussion:}

Neck space abscess is a challenging problem because of variable clinical manifestations, which can be presented with potentially lethal complications such as upper airway obstruction, mediastinitis, thrombosis of the internal jugular vein, septic shock, and death. Furthermore, these conditions commonly result in complex clinical presentation. Thus, understanding the correlation between the clinical findings and the extended pathway is an important step in avoiding an underestimated diagnosis. In addition, discovering the etiology, comorbidity, specific bacterial pathogens, and other associated factors, which increase disease severity, is needed for effective treatments and decreased complication rates.

In our study 54 patients who presented in ENT OPD between October 2010 to October 2012 and who were diagnosed as having deep neck abscesses either by needle aspiration or radiological studies were included. In present study of 54 patients total 56 spaces were involved. Most common space involved was peritonsillar in $22(40.74 \%)$ patients followed by submandibular space in $12(22.22 \%)$ patients.

Consistent with these findings is the study conducted by Khaled Al-Noury et al (2010) ${ }^{[3]}$ who reviewed CT images of fifty six patients, most common space involved was peritonsillar space in 24 patients (42.9\%) followed by parapharyngeal space in 14 patients (25\%) and submandibular space in 14 patients (25\%).

Male predominance was noted because of poor oral hygiene in male as out of 19 patients having odontogenic etiology of abscess 11 were male and out of 22 patient having tonsillopharyngitis as etiology 12 were male.

Similar results were found by Gerd Jurgen Ridder et al (2005) ${ }^{[4]}$ who conducted a clinical study on 234 patients of deep neck infections diagnosed between 1997 to 2005. There were 131 (56\%) male and 103 (44\%) female patients. Male:Female ratio was 1.27:1

most common symptoms were painful mouth opening in $94.44 \%$ patients and fever in $95.59 \%$ patients. Trismus was present in $85.18 \%$ patients and $61.11 \%$ patients presented with either unilateral or bilateral neck swelling. Other symptoms were dysphagia and odynophagia in $62.96 \%$, toothache in $35.18 \%$.

Similar results were found by Pei-Ti Tan et al (2001) ${ }^{[5]}$ who conducted study over 68 patients of deep neck infections. Most common symptom at presentation was fever (63\%) and neck pain (47.1\%). Most common sign was neck mass $(61.8 \%)$.

Special attention was given to presence or absence of trismus as it was found to be an important finding because it posed difficulty in clinical evaluation of internal extent of abscess and for maintenance of airway while performing drainage procedures. It was present in 11 out of 12 cases of submandibular abscess and 21 out of 22 cases of peritonsillar abscess. In cases of peritonsillar abscess presence of trismus posed additional difficulty in differentiating between peritonsillar cellulitis and peritonsillar abscess as simplest method to differentiate between these two is by needle aspiration.

In our study most common etiology was found to be upper airway infection ( Tonsillopharyngitis) in 22 patients $(40.74 \%)$ followed by odontogenic cause in 19 patients (35.18\%). All cases having tonsillopharyngitis as etiology presented with peritonsillar abscess. In 4 cases $(7.40 \%)$ etiology could not be identified.

Similar results were found in a study conducted by Paulo Boscolo Rizzo et al (2012). ${ }^{[6]}$ In their study the source of infection was identified in 297 patients (81.4\%): the most common cause was a pharyngitis $(\mathrm{n}=$ $119 ; 32.6 \%)$, followed by dental infection $(\mathrm{n}=102 ; 27.9 \%)$.

Maximus cases in which abscess location was accessible were easily diagnosed by needle aspiration. Cases with unaccessible locations were diagnosed by USG and CT scans.

In our study 43 ( $77.78 \%)$ isolates were found on pus culture of 54 cases. In $12(22.22 \%)$ cases no organism were found. Most common organism found was coagulase positive staphylococcus in $29.62 \%$ cases 
followed by coagulase negative staphylococcus in $16.66 \%$ cases. Streptococci were found in $11.11 \%$ cases. Multiple organisms were found in only one case of peritonsillar abscess. Though one case was a diagnosed case of tuberculosis, acid fast bacilli were not seen on AFB staining of pus.

Association of anaerobic organisms with neck space abscesses has been proved by many reports ${ }^{[4]}$ but because of unavailabity of anaerobic culture facilities pus was not cultured for the same. This deficiency in our study was to some extent compensated by looking for foul smell in pus. In $72 \%$ cases there was presence of foul smell.

Though in many studies of peritonsillar abscess most common pathogen was streptococcus ${ }^{[7,8]}$ in our study pus from cases of peritonsillar abscess most commonly showed coagulase +ve staphylococcus $(44.44 \%)$, followed by streptococcus $(27.77 \%)$ and coagulase $-\mathrm{ve}$ staphylococcus $(22.22 \%)$. coagulase $+\mathrm{ve}$ staphylococcus was also commonly isolated from cases of submandibular abscess. This was consistent with study by James M. Coticchia et al ( 2004$)^{[2]}$ who found staphylococcus aureus in $42 \%$ cases of submandibular abscess cases.

Sensitivity was highest for aminoglycosides and cephalosporins (78.57\% and $71.42 \%$ respectively) while same were having least resistance (21.42\% and $28.57 \%$ respectively).

Resistance was highest for erythromycin and ciprofloxacin $(61.90 \%$ each) and same group showed least sensitivity (38.09\% each).

When individual organisms were considered then aminoglycosides were most effective against coagulase positive staphylococcus ( $93.75 \%$ sensitive and $6.25 \%$ resistant) and coagulase negative staphylococcus (100\% sensitive). Streptococci were most susceptible to cephalosporins ( $83.33 \%$ sensitive and $16.66 \%$ resistant). Penicillins were most effective against coagulase negative staphylococcus (100\% sensitive) and E. Coli (100\% sensitive).

Needle aspiration was performed in 22 cases ( 40.74\%) out of which 20 cases were of peritonsillar abscess and 2 were of submandibular abscess.

All peritonsillar abscesses were treated with needle aspiration except in one cases in which patient presented with burst abscess and only dilatation was done. So though the criterion for proceeding for incision and drainage was requirement of third aspiration, none of the cases of peritonsillar abscess required third aspiration. In most of the patients, aspiration of pus brought about immediate relief of odynophagia and trismus.

Incision and drainage was performed in $26(48.14 \%)$ patients.

Only dilatation was done in 6 patients who presented with burst abscess.

Dental extraction was performed in all 19 cases having odontogenic etiology as soon as they gained adequate mouth opening and before discharging them so that to avoid recurrence due to negligence and unawareness on the part of patients.

In all 4 cases who presented with recurrent peritonsillar abscess interval tonsillectomy was done after 6 weeks.

\section{Summary And Conclusion:}

54 patients diagnosed as having neck space abscess were included in this study.

- Total 56 spaces were involved with multiple space involvement in two patients.

- There was slight male predominance, male as to female ratio being 1.16:1 with most common age group being 11-20 yrs (22.22\%).

- Peritonsillar abscess was most commonly found $(40.74 \%)$ followed by submandibular space $(22.22 \%)$ and tonsillopharyngitis was most common etiology $(40.74 \%)$.

- Most common symptoms were painful mouth opening (94.44\%) and fever (92.59\%).

- Odontogenic cause was significantly associated with submandibular abscess ( 10 out of 12) and Ludwig's angina (5 out of 8 )

- Most common organism involved was found to be coagulase positive staphylococcus (29.62\%) and most efficient antibiotic was aminoglycoside (78.57\% sensitive and $21.42 \%$ resistant).

- Needle aspiration was performed in 22 cases ( $40.74 \%$ ) out of which 20 cases were of peritonsillar abscess, 1 was of parotid abscess and 1 was of submandibular abscess. Incision and drainage was performed in $26(48.14 \%)$ patients.

- Deep neck abscess can occur in all age groups and in immunocompetent patient without any co-morbid illness.

- Tonsillopharyngeal and dental infections should not be taken for granted and should be treated early.

- Aminoglycosides should be a part of empirical treatment.

- If facilities of anaerobic culture not available then it is always better to add antibiotics against anaerobic bacteria e.g. metronidazole. 
- While working in a rural area if dental etiology is found then it is always good to offer dental extraction as soon as patient regains adequate mouth opening in order to prevent recurrence due to negligence and unawareness.

- Maximum patients of deep neck abscess are having decrease mouth opening making it difficult to examine internal extent and maintaining airway. So it's always better to adopt all or none technique i.e. either you perform drainage procedures under general anaesthesia with a tracheostomy in order to secure airway or better way go for surface anaesthesia with minimal sedation so that patient will not aspirate if abscess accidentally bursts internally.

\section{Acknowledgement;}

We are very much thankful to our respected H.O.D. and prof. Dr. A.M. Pawde sir.

\section{References}

[1]. Kaluskar S, Bajaj P, Bane P. Deep space infections of neck. Indian J Otolaryngol Head Neck Surg. 2007 Mar;59(1):45-8.

[2]. Coticchia JM, Getnick GS, Yun RD, Arnold JE. Age-, site-, and time-specific differences in pediatric deep neck abscesses. Arch Otolaryngol Head Neck Surg. 2004 Feb;130(2):201-7.

[3]. Khaled Al-Noury, Alsaid Lotfy. Deep Neck spaces Radiology And review Of Deep Neck Infections At King Abdulaziz University hospital. Egyptian Journal Of Ear, Nose, Throat And Allied sciences. 2010 Dec; 11: 69-7

[4]. Ridder GJ, Technau-Ihling K, Sander A, Boedeker CC. Spectrum and management of deep neck space infections: an 8-year experience of 234 cases. Otolaryngol Head Neck Surg. 2005 Nov;133(5):709-14.

[5]. Tan P, Chan LY, Huang YC. Deep Neck Infections In Children. J Microbiol Immunol Infect. 2001; 34:287-292

[6]. Boscolo-Rizzo P, Stellin M, Muzzi E, Mantovani M, Fuson R, Lupato V, Trabalzini F, Da Mosto MC. Deep neck infections: a study of 365 cases highlighting recommendations for management and treatment. Eur Arch Otorhinolaryngol. 2012 Apr;269(4):1241-9.

[7]. Tyagi V, Kaushal A, Deepika G, Samistha D, Nagpure P. Treatment Of Peritonsillar Abscess-A Prospective Study Of Aspiration Verses Incision And Drainage. Calicut Medical Journal 2011; 9(3):e3

[8]. Ophir D, Bawnik J, Poria Y, Porat M, Marshak G. Peritonsillar abscess. A prospective evaluation of outpatient management by needle aspiration. Arch Otolaryngol Head Neck Surg. 1988 Jun;114(6):661-3. 